\title{
The New Science of Abuse-Deterrence Assessment of Pharmaceutical Products; FDA Proposed Guidance and Category 1 Laboratory Studies
}

\author{
Cone EJ, Buchhalter AR*, Henningfield JE, Schnoll SH
}

PinneyAssociates, 4800 Montgomery Lane, Suite 400, Bethesda, USA

\begin{abstract}
The problem of prescription drug abuse in the United States began more than 100 years ago and became epidemic in the last decade producing many tragic consequences with incredible societal costs. Drug overdoses have doubled over the last 10 years and now surpass deaths from motor vehicle accidents (DHHS, 2013). Congress reacted to this ongoing tragedy in 2012 by mandating the Food and Drug Administration (FDA) promulgate guidelines for the development of abuse-deterrent formulations (ADFs) for prescription opioid medications as one of the approaches to reducing this problem. The FDA responded in 2013 by issuing a draft guidance to industry for assessment of ADFs (FDA, 2013). The 2013 guidance expanded initial guidance proposed in 2010 (FDA, 2010).FDA is expected to issue final guidance for industry in the latter part of 2014.
\end{abstract}

\section{Introduction}

The rationale for ADFs is to maintain opioid efficacy for patients while improving the safety of the product by deterring abuse and, in turn, preventing overdose and deaths. The 2013 FDA guidance focuses upon formulation changes that may reduce misuse/abuse of opioids, but acknowledges other approaches including combination products and prodrugs. These approaches are summarized in Table 1 along with examples of products that exhibit some of these features. Please note, while the approaches referenced in the guidance are comprehensive, they are not exhaustive. For example, one approach not specified in the guidance, and thus not included in Table 1, involves new chemical entities (NCEs). This approach is exemplified by Nektar Therapeutics' NKTR-181, a novel mu-opioid analgesic engineered using Nektar's small molecule polymer conjugate technology. It has been designed to enter the central nervous system at a markedly slower rate relative to other opioids.

The pathway to approval and appropriate labeling of ADFs is founded upon studies outlined by the 2010 and 2013 FDA guidances that seek to define the abuse potential of the product as well as the strengths and weaknesses of the formulation. The 2013 FDA guidance lists three types of premarketing studies (Categories 1-3) that may be necessary "...to obtain a full and scientifically rigorous understanding of the impact of a technology or technologies on a product's abuse potential..." and one for postmarketing (Category 4) that assesses the impact of an ADF on real-world abuse. These studies are as follows:

Category 1: Laboratory-based in vitro manipulation and extraction studies

Category 2: Pharmacokinetic studies

Category 3: Clinical abuse potential studies

Category 4: Post marketing studies to determine whether the abusedeterrent product produces a significant reduction in population-based estimates of abuse

Additionally, the 2013 guidance incentivizes industry development of ADFs by offering four possible categories of tiered labeling. Studies designed around the four Category assessments are intended to lead, in somewhat similar order, to four general tiers of label claims. The tiers are as follows:

Tier 1: The product is formulated with physicochemical barriers to abuse
Tier 2: The product is expected to reduce or block effect of the opioid when the product is manipulated

Tier 3: The product is expected to result in a meaningful reduction in abuse

Tier 4: The product has demonstrated reduced abuse in the community

Design and execution of Category 1-4 studies presents new challenges to industry. Among the premarketing studies suggested by the guidance, pharmacokinetic studies (Category 2) and human abuse liability studies (Category 3) are well-defined in the scientific literature [1-9]; however Category 1 studies represent a new category of scientific studies that have received little attention and study. The challenge of Category 1 studies lies in the need to translate "real-world" abuser practices into robust, scientific laboratory studies. The ingenuity seen in abuser practices includes many variations of tampering and the possibilities appear almost limitless. Many abusers attempt to crush tablets and capsules into fine powders for intranasal and oral administration ("parachuting") and extract active ingredients from tablets and capsules with household solvents for injection, oral, and rectal use. Some abusers prefer the smoking route for the rapid onset of drug effects without the use of needles. For those formulations containing an antagonist added to block drug effects when a formulation is altered from its intended mode of use, abusers attempt to isolate the active ingredient by physical and chemical means. Patches for transdermal application may be disassembled exposing the active drug layer for direct oral and sublingual application, vaporization for inhalation,

*Corresponding author: Buchhalter AR, Director, Abuse-Deterrent Drug Products, PinneyAssociates, 4800 Montgomery Lane, Suite 400, Bethesda, MD 20814, USA Tel: 301.718.8440; E-mail: abuchhalter@pinneyassociates.com

Received October 08, 2014; Accepted October 30, 2014; Published Decembe 12, 2014

Citation: Cone EJ, Buchhalter AR, Henningfield JE, Schnoll SH (2014) The New Science of Abuse-Deterrence Assessment of Pharmaceutical Products; FDA Proposed Guidance and Category 1 Laboratory Studies. Pharm Anal Acta 5: 317. doi:10.4172/2153-2435.1000317

Copyright: $\odot 2014$ Cone EJ, et al. This is an open-access article distributed under the terms of the Creative Commons Attribution License, which permits unrestricted use, distribution, and reproduction in any medium, provided the original author and source are credited. 
Citation: Cone EJ, Buchhalter AR, Henningfield JE, Schnoll SH (2014) The New Science of Abuse-Deterrence Assessment of Pharmaceutical Products; FDA Proposed Guidance and Category 1 Laboratory Studies. Pharm Anal Acta 5: 317. doi:10.4172/2153-2435.1000317

Page 2 of 3

Table 1: Formulation Changes that may Reduce Misuse/Abuse of Opioids (FDA, 2013)

\begin{tabular}{|c|c|c|}
\hline Category & Principle & Examples \\
\hline Physical/chemical barriers & $\begin{array}{l}\text { Physical barriers that prevent chewing, crushing, or grinding (e.g., tablet hardness). } \\
\text { Chemical barriers that resist extraction and injection (e.g., gelling in water). }\end{array}$ & OxyContin $^{\circledR}$, Nucynta $^{\circledR}$, Exalgo $^{\circledR}$, Opana $^{\circledR}$ ER \\
\hline Agonist/antagonist combinations & $\begin{array}{l}\text { Addition of an opioid antagonist (e.g., naloxone, naltrexone) that reduces or } \\
\text { eliminates euphoria or drug "high". }\end{array}$ & Embeda $^{\mathrm{TM}}$, Suboxone \\
\hline Aversion & Addition of a substance (e.g., niacin, SLS) that produces an unpleasant effect. & Oxecta $^{\circledR}$ \\
\hline Delivery system & Drug depots and implants & Probuphine \\
\hline Prodrug & $\begin{array}{l}\text { An opioid prodrug that lacks opioid activity and must be transformed in the body to } \\
\text { produce activity }\end{array}$ & \\
\hline Combination & Multiple methods incorporated into the formulation & Oxecta ${ }^{\circledR}$ \\
\hline
\end{tabular}

${ }^{*}$ Abbreviation: SLS $=$ Sodium Lauryl Sulfate.

or extracted for injection. Attempts may be made to chemically alter NCEs or new molecular entities to enhance their activity or to use as precursors for conversion to a known drug of abuse.

The purpose of Category 1 studies is to serve as the foundation that both informs industry about the strengths and weaknesses of an $\mathrm{ADF}$ and supports investigators regarding how Category 2 and 3 studies should be performed. In addition, Category 1 studies should be "predictive" of how ADFs will withstand tampering attempts by patients, caregivers, and abusers. The 2013 FDA guidance considers Category 1 studies as "an evolving science" that must be developed and calls for "robust scientific" methods to be employed. Some investigators have called for standardized testing and reporting so that products can be accurately assessed [6] but there is reason to keep a flexible, iterative approach to the design of Category 1 studies.Each formulation and active ingredient has peculiar physicochemical characteristics that belie standardization. Consequently, Category 1 assessments that do not fully explore the chemical boundaries of a product may yield limited results and overlook important formulation weaknesses.

A model for comprehensive Category 1 testing methods is needed to avoid approval of ADFs with significant weaknesses entering the commercial market. One such model, which merits discussion, was successfully utilized in the assessment of reformulated OxyContin [3]. We believe that the design of scientifically rigorous Category 1 studies of ADFs should begin with considerations from multiple knowledge domains encompassing the following areas:

- Physicochemical properties of the active pharmaceutical ingredient (API) and formulation excipients

- Abuse potential of API

- $\quad$ Abuser patterns relating to tampering practices and preferred routes of administration

A valid Category 1 assessment should challenge a product in ways that are known to be practiced or may plausibly be used by drug abusers in "real-world" settings. Generally, simple one-step methods are preferred in most abuse attempts, but highly motivated abusers will attempt complex, multi-step methods. The complex methods of manipulation would most likely be attempted by individuals with experience with and access to suitable chemicals and solvents that are less commonly found in the household. Conceptually, Category 1 studies consist of the following general types of assessments:

\section{Physical manipulations}

- Tablets and capsules: crushing/grinding tablets, particle size determinations, band uniformity, effects of heating and freezing
- Patches: cutting/separating patches

2. Extraction experiments

- One-step extraction with solvents displaying a variety of chemical properties

- Multi-step extraction and isolation procedures

3. Injectability

- Extraction in small aqueous based solvents for injection

- Effects of heating, shaking (i.e., agitation), and extraction time on quantity and quality of extract

4. Smokeability

- Vaporization studies of APIs and formulation matrices

5. Dose-dumping studies

- Dissolution studies to determine effects of co-ingestion of ethanolic beverages

6. Specialized assessments that may be needed for specific APIs and formulations

- Thermal stressing effects (effects of heating on excipients and polymeric matrices) on extraction efficiency, viscosity, and injectability

- Solution viscosity measurements

- Chemical challenges that may separate/inactivate antagonists/ irritants

- Chemical and enzymatic challenges that may convert prodrugs or NCEs to another molecular species with greater activity or more desirable characteristics

- Free-base isolation studies

- Solubility studies of APIs and excipients

Comprehensive Category 1 assessments made during ADF development would serve an innovator company (and investors) by informing them of possible changes that would make the product safer and more resistant to abuse. Results from Category 1 studies at the final formulation stage of development provide the foundational basis for tiered labeling. Category 1 studies also inform and support the design of Category 2 and 3 studies. After approval, ADFs will be subjected to myriad tampering attempts. If ADFs prove successful in reducing abuse in the community ("real-world settings"), the FDA guidance offers the possibility of an additional tiered label (i.e., Tier 4 label; based on Category 4 studies). The Tier 4 label may be considered the highest level of regulatory approval and is likely to be approved 
Citation: Cone EJ, Buchhalter AR, Henningfield JE, Schnoll SH (2014) The New Science of Abuse-Deterrence Assessment of Pharmaceutical Products; FDA Proposed Guidance and Category 1 Laboratory Studies. Pharm Anal Acta 5: 317. doi:10.4172/2153-2435.1000317

Page 3 of 3

only for those highly successful ADFs that present significant barriers to abuse by multiple routes of administration as demonstrated by extensive epidemiological data. For new products or formulations, the ability to integrate the Category 1-3 with the Category 4 epidemiologic data will be essential in determining whether it is feasible to obtain a Tier 4 designation. Unfortunately, FDA has provided little guidance as to what criteria will be used to determine whether a product will obtain Tier 4 labeling. For instance, an ADF that demonstrated marked reductions in abuse in the community (across several measures; based on comparisons contrasting postmarketing surveillance and baseline data [1]), was not granted Tier 4 labeling by FDA. ADFs with lower initial baseline rates and substantially lower market presence may find documenting reductions in abuse more challenging.

Clearly, methods for Category $1 \mathrm{ADF}$ assessments represent a new type of science that must continue to evolve and develop. Although assessments intended to document the nature and level of effort required to defeat products may appear counter-intuitive to product developers, the information gained from scientific studies that simulate patient and abuser tampering practices will foster development of safer products. The draft guidance and FDA's flexible approach to "incentivizing" and "evaluating" abuse-deterrent product development is leading to the appearance of a broad array of novel products with the diversity needed to improve safety for patients and mitigate widespread abuse of prescription products.

\section{Disclosures}

PinneyAssociates provides consulting support to pharmaceutical companies on in vitro and abuse liability assessment, drug scheduling, postmarketing surveillance and risk management.
Development and preparation of this commentary was supported solely by PinneyAssociates.

\section{References}

1. Butler SF, Cassidy TA, Chilcoat H, Black RA, Landau C (2013) Abuse rates and routes of administration of reformulated extended-release oxycodone: Initial findings from a sentinel surveillance sample of individuals assess for substance abuse treatment. J Pain 14: 351-358.

2. Carter LP, Griffiths RR (2009) Principles of laboratory assessment of drug abuse liability and implications for clinical development. Drug Alcohol Depend 105: S14-S25.

3. Cone EJ, Giordano J, Weingarten B (2013) An iterative model for in vitro laboratory assessment of tamper deterrent formulations, Drug Alcohol Depend 13: 100-105.

4. Griffiths RR, Bigelow GE, Ator NA (2003) Principles of initial experimental drug abuse liability assessment in humans. Drug Alcohol Depend 70: 41-54.

5. Grudzinskas C, Balster RL, Gorodetzky CW, Griffiths RR, Henningfield JE, et al (2006) Impact of formulation on the abuse liability, safety and regulation of medications: the expert panel report. Drug Alcohol Depend 83: 77-82.

6. Katz NP, Buse DC, Budman SH, Wing VS, Fernandez KC, et al. (2006) Development and preliminary experience with an ease of extractability rating system for prescription opioids. Drug Dev Ind Pharm 32: 727-746.

7. U.S. Department of Health and Human Services. Addressing Precription Drug Abuse in the United States Current Activities and Future Opportunities. 2013. Washington, DC

8. U.S. Food and Drug Administration. Guidance for Industry Abuse-Deterrent Opioids - Evaluation and Labeling. 2013. U.S. Department of Health and Human Services.

9. U.S. Food and Drug Administration. Guidance for Industry Assessment of Abuse Potential of Drugs. 2010. U.S. Department of Health and Human Services. 